\title{
Aglaomorpha quercifolia (L.) Hovenkamp \& S. Linds a Wild Fern Used in Timorese Cuisine ${ }^{\dagger}$
}

\author{
Hermenegildo R. Costa ${ }^{1,2,3}$, Inês Simão ${ }^{2}{ }^{(D}$, Helena Silva $^{2} \mathbb{D}$, Paulo Silveira ${ }^{2} \mathbb{D}$, Artur M. S. Silva ${ }^{1}(\mathbb{D}$ and \\ Diana C. G. A. Pinto ${ }^{1, *(1)}$
}

1 LAQV-REQUIMTE \& Department of Chemistry, Campus de Santiago, University of Aveiro, 3810-193 Aveiro, Portugal; hrcosta@ua.pt (H.R.C.); artur.silva@ua.pt (A.M.S.S.)

2 CESAM-Centre for Environmental and Marine Studies \& Department of Biology, Campus de Santiago, University of Aveiro, 3810-193 Aveiro, Portugal; ines.simao@ua.pt (I.S.); hsilva@ua.pt (H.S.); psilveira@ua.pt (P.S.)

3 Faculty of Education, Arts and Humanities, National University Timor Lorosa'e (UNTL), Avenida Cidade de Lisboa, Dili, East Timor

* Correspondence: diana@ua.pt

+ We dedicate this article to the memory of the prestigious pteridologist Peter Hans Hovenkamp (1953-2019), member of the Naturalis Biodiversity Center (Leiden, The Netherlands), chief editor of Blumea, among other merits. He gave a significant contribution to help H.R.Costa in his efforts towards elaborating a checklist of Timor's ferns, which paved the way to the present article.

Citation: Costa, H.R.; Simão, I.; Silva, H.; Silveira, P.; Silva, A.M.S.; Pinto, D.C.G.A. Aglaomorpha quercifolia (L.) Hovenkamp \& S. Linds a Wild Fern Used in Timorese Cuisine . Foods 2021, 10, 87. https://doi.org/10.3390/ foods10010087

Received: 20 November 2020 Accepted: 30 December 2020 Published: 4 January 2021

Publisher's Note: MDPI stays neutral with regard to jurisdictional clai$\mathrm{ms}$ in published maps and institutional affiliations.

Copyright: (C) 2021 by the authors. Licensee MDPI, Basel, Switzerland. This article is an open access article distributed under the terms and conditions of the Creative Commons Attribution (CC BY) license (https:// creativecommons.org/licenses/by/ $4.0 /)$.

\begin{abstract}
Aglaomorpha quercifolia (L.) Hovenkamp \& S. Linds is an extensively used species in traditional medicinal systems in several areas of the world due to some important medicinal properties such as antioxidant, antibacterial, analgesic, and anti-inflammatory activities. In East Timor, different parts of this fern are used either as remedies or as food. The ingestion of a broth made from its rhizome improves lactation, and young fronds of this fern are boiled and eaten with rice by the locals. Nevertheless, its chemical profile is far from being established. The present work aims to establish the chemical profile of both rhizomes and leaves $n$-hexane extracts by Gas Chromatography- Mass Spectrometry (GC-MS). The results showed the leaves richness in fatty acids with interesting nutritional values $(\omega-6 / \omega-3=0.68, \mathrm{AI}=0.59, \mathrm{TI}=0.30)$, being linolenic acid $(253.71 \pm 0.93 \mathrm{mg} / \mathrm{g}$ dry leaves) and palmitic acid ( $237.27 \pm 0.59 \mathrm{mg} / \mathrm{g}$ dry leaves) the significant compounds in the extract. Whereas the rhizome extract is mostly rich in terpenoids, such as steroid, cycloartane, and hopanoid derivatives, being hop-16-ene ( $166.45 \pm 0.53 \mathrm{mg} / \mathrm{g}$ dry rhizome) and $\beta$-sitosterol $(50.76 \pm 0.11 \mathrm{mg} / \mathrm{g}$ dry rhizome) the major compounds. Several compounds are reported for the first time in the species, and the data herein reported contributes to confirming the species nutritional value.
\end{abstract}

Keywords: Aglaomorpha quercifolia; GC-MS profile; rhizome; leaves; $n$-hexane extract; fatty acids; terpenoids; linolenic acid; hop-16-ene

\section{Introduction}

Aglaomorpha quercifolia (L.) Hovenkamp \& S. Linds., [syn. (Drynaria quercifolia (L.) J.Sm., J. Bot. (Hooker)] [1] is an epiphytic, occasionally epilithic medicinal pteridophyte with a short-creeping rhizome, dimorphic fronds, and pinnatifid lamina. It belongs to the Polypodiaceae family, which includes 65 genus and 165 species worldwide [2]. A. quercifolia occurs in primary and secondary forests, savannas, and plantations (such as rubber and coconut), but it can also be found along sideroads [3].

Aglaomorpha quercifolia is an extensively used species in traditional medicinal systems in several areas of the world. For example, in India, it is used by tribal communities to cure several different conditions. The juice produced from the rhizome and fronds is taken for body pain [4] and intestinal worms [5]. This fern is also used to treat throat infections, tuberculosis [6], jaundice, dysentery, and typhoid fever [7]. In Bangladesh, several parts of this fern have been used to treat jaundice [8], gonorrhea [9], diabetes [10], and malaria [11]. 
In East Timor, this fern rhizome is used either as a remedy to treat stomach pain or as food. It is believed that the ingestion of a broth made from its rhizome helps young moms producing more milk [12]. The rhizome is also consumed as a tea, and the young fronds of this fern are boiled and eaten with rice by the locals [12]. A paste made from the rhizome is massaged onto people with malaria [13].

The above-mentioned vast range of traditional uses concerning A. quercifolia are most certainly related to its many medicinal properties, such as antioxidant [14], antibacterial [15], analgesic [16], anti-inflammatory [17], anthelmintic [18], antipyretic [19], and antirheumatic [20]. These medicinal properties must be directly related to the secondary metabolites produced by the plant. Although these metabolites are not essential to the plant's life, they contribute directly to its fitness [21] and the interactions between the organism and the environment [22]. It is known that several classes of secondary metabolites with different functions in the plant are responsible for the plant's traditional medicine applications.

In terms of its secondary metabolites, A. quercifolia is not an extensively studied species. Studies involving methanolic or ethanolic extracts of the whole plant or the rhizome revealed the identification of several compounds [23-25]. Due to the use of polar solvents in the extraction, several reported compounds are polyphenolic, and others seemed not to be secondary metabolites. So, concerning the use of A. quercifolia in traditional medicine and nutrition, further studies focused on the plant's lipophilic constituents are needed to support its traditional use and possible medicinal properties.

Thus, this study aimed to establish the GC-MS profile of both $A$. quercifolia rhizomes and leaves $n$-hexane extract and simultaneously confirm the species' nutritional and medicinal value.

\section{Materials and Methods}

\subsection{Plant Collection}

Specimens of Aglaomorpha quercifolia (L.) Hovenkamp \& S. Linds. were collected from Dare (Vera Cruz, Dili, East Timor) in July 2016. A voucher specimen was identified by the plant taxonomist Paulo Silveira and deposited in the Herbarium of the Department of Biology, University of Aveiro, Portugal (AVE), under the reference number AVE7891 (Costa HR 87).

Several plants were collected (around 100 plants), the plant rhizome and leaves were separated, washed, and dried at room temperature for 7 days. Six samples having ten plant parts were powdered using an electrical blender.

\subsection{Extracts Preparation}

For the extraction in $n$-hexane, the amount of plant was determined on a precision scale, RADWAG WLC 6/A2, with a precision of $0.1 \mathrm{~g}$. In the process, $100 \mathrm{~mL}$ of $n$-hexane for each $10 \mathrm{~g}$ of the plant was used. In Table 1, the weights of plant powder and the amount of $n$-hexane are listed. The plant parts were put into an Erlenmeyer flask, a magnetic stirrer was added, and the flasks were placed on a stirring plate. The $n$-hexane was added, see volume in Table 1, and the stirring was started at a speed of $600 \mathrm{rpm}$. Because some compounds can decompose under the light influence, the flasks were covered with aluminum foil in advance.

Table 1. Dry weight of A. quercifolia and added volume of the solvent.

\begin{tabular}{ccccc}
\hline Part of Plant & DW $(\mathbf{g})$ & V (mL) & HeW (g) & PyHe (\%) \\
\hline Leaves & $10.01 \pm 0.05$ & $300.0 \pm 0.1$ & $0.58 \pm 0.03$ & $5.79 \pm 0.09$ \\
Rhizomes & $10.03 \pm 0.05$ & $300.0 \pm 0.1$ & $0.37 \pm 0.01$ & $3.69 \pm 0.05$ \\
\hline
\end{tabular}

$\overline{\mathrm{DW}}=$ Dry weight of the plant part used; $\mathrm{V}=$ Volume of $n$-hexane added; HeW = Hexane extract weight; $\mathrm{PyHe}=$ Percentage yield of the hexane extract. 
One extraction ran for $48 \mathrm{~h}$, and the solvent was changed at least twice until no intensive color and increase of extraction weight of the solvent occurred. After an extraction cycle, the solvent was filtered and evaporated. After the three extraction cycles, the extracts were dried until mass consistency before further usage. The procedure was repeated for two more samples, and the average weights of $n$-hexane dried extracts (after constant mass) are shown in Table 1.

\subsection{Standards and Reagents}

Several pure compounds were used as standards to ensure the identification of the phytochemicals and to perform the calibration curves for quantification purposes. Tetradecane $(99 \%)$, hexadecane $(99.5 \%)$, tetracosane $(99 \%)$, octadecane $(99 \%), 1$-monopalmitin $(>99 \%), \beta$ sitosterol (98\%), lupeol, $5 \alpha$-cholestan-3 $\beta$-ol (99\%), D-mannitol (98\%), 1-tetradecanol (98\%), sorbitol (99\%), D-(+)-galactose (>99\%), D-(+)-mannose (>99\%), D-(+)-xylose (>99\%), D- $(-)$ ribose $(>99.5 \%)$, D-fructose $(99 \%)$, sucrose $(>99 \%)$, maltose $(>98 \%)$, stigmasterol $(97 \%)$, cycloartenol (>99\%), campesterol (95\%), lupeol (99\%), ursolic (98\%), oleanolic (98\%), palmitic $(\geq 99 \%)$ and stearic (99\%) acids, were purchased from Sigma-Aldrich (St. Louis, MO, USA). Malonic acid (98\%), linoleic acid ( $\geq 99 \%)$, and glycerol (>99\%) were purchased from BDH analytical chemicals (London, UK), D-(-)-cellobiose (>98\%), $\alpha$ - and $\beta$-tocopherol (98\%) from Merk (Darmstadt, Germany), and D-(-)-arabinose (>99\%) from Fluka (Bucharest, Romania) while, eicosane, docosane, hexatriacontane, and n-paraffin mixtures (C5-C8, C7-C10, C10-C16, C18-C24, C24-C36, C25-C35) were supplied by Supelco Inc. (Bellefonte, PA, USA).

For extraction, hexane pro-analysis (p.a) was used while dichloromethane (p.a.) (DCM) was employed to dissolve the extracts. Pyridine p.a., N, O-bis(trimethylsilyl)trifluoroacetamide (BSTFA) (99\%) and trimethylsilyl chloride (TMSCl) (99\%) (Sigma-Aldrich) were applied in the sample derivatization by silylation.

\subsection{Gas Chromatography-Mass Spectrometry Analysis}

The GC-MS analysis of the $n$-hexane extracts was done using a Shimadzu GCMSQP2010 Ultra system equipped with autosampler AOC-20i, ion source: electronic impact high-performance Quadrupole mass filter. Separation of the compounds was carried out in a DB-5J\&W capillary column $(30.0 \mathrm{~m}$ in length $\times 0.25 \mathrm{~mm}$ in diameter $\times 0.25 \mu \mathrm{m}$ thickness of the film). The spectroscopic detection from the mass spectrometer utilized $0.1 \mathrm{kV}$ electron ionization. Helium was used as a carrier gas with a column flow of $1.18 \mathrm{~mL} / \mathrm{min}$. GCinjection temperature was set to $\vartheta=320^{\circ} \mathrm{C}$ and split ratio of 50 was applied to an injection volume of $1 \mu \mathrm{L}$. The mass spectrometer ion source temperature was set to $\vartheta=250{ }^{\circ} \mathrm{C}$ and the interface temperature to $\vartheta=300{ }^{\circ} \mathrm{C}$.

The extracts were weight with approximately $\mathrm{m}=20 \mathrm{mg}$ on an analytical scale into a tube. DCM was used as a solvent and $n$-tetracosane as an internal standard, added to the tube with $1 \mathrm{~mL}$ in total. The extracts were then dissolved in an ultra-sonic bath. For the silylation, $250 \mu \mathrm{L}$ pyridine, $250 \mu \mathrm{L}$ BSTFA, and $50 \mu \mathrm{L}$ TMSCl were added. The mixture was maintained in a water bath at $\vartheta=70{ }^{\circ} \mathrm{C}$ for $45 \mathrm{~min}$ being the hydroxy and the carboxy groups present in each secondary metabolite converted to trimethylsilyl (TMS) ethers and esters, respectively. Afterwards were injected twice in the GC-MS apparatus. The silylation reagents quantity, the water bath temperature and the reaction time were previously optimized to ensure a total conversion of all compounds with hydroxy groups into the correspondent TMS derivatives.

The chromatographic conditions were as follows: start time of record at $6.5 \mathrm{~min}$; initial temperature $\vartheta=90^{\circ} \mathrm{C}$, hold for $4.00 \mathrm{~min}$; temperature rate, $16^{\circ} \mathrm{C} / \mathrm{min}$ up to $\vartheta=180{ }^{\circ} \mathrm{C}$; temperature rate, $6^{\circ} \mathrm{C} / \mathrm{min}$ up to $\vartheta=250{ }^{\circ} \mathrm{C}$; followed by temperature rate, $3{ }^{\circ} \mathrm{C} / \mathrm{min}$ up to $\vartheta=300{ }^{\circ} \mathrm{C}$ and then hold for $5.00 \mathrm{~min}$.

From the total ion chromatogram, the peaks were identified by comparing their mass spectra with the mass spectra libraries NIST 2014, NIST 2008, and WILEY 2007, and with mass spectra fragmentation published in the literature [26-30]. If possible, it was also 
compared with the retention time and mass spectra of standard compounds injected in the same chromatographic conditions. Furthermore, identification of some compounds was done using the retention index relative to $n$-alkanes (C5-C36) injected in the same chromatographic conditions and using the Equation (1). Where $\mathrm{z}$ is the number of carbon atoms in the alkane before the unknown compound and $\mathrm{Z}$ the number of the longer alkane. The retention time is $t_{r}[31]$ :

$$
I=100 \cdot\left[z+(Z-z) \cdot \frac{t_{r(\text { unknown })}-t_{r(z)}}{t_{r(Z)}-t_{r(z)}}\right] .
$$

For quantification purposes, four independent replicates of each sample were submitted to silylation procedure and each one injected in duplicate. The internal standard method was applied and the amount of metabolites present was achieved from the calibration curves obtained with the most closed pure standard compounds available or its TMS derivatives (if they have hydroxy groups). All the injected samples and standards solutions contain a fixed quantity of internal standard (tetracosane). The calibration curves were obtained by injection of at least six different concentrations $\left(5 \mu \mathrm{g} \mathrm{mL}-1\right.$ to $\left.1.5 \mathrm{mg} \mathrm{mL}^{-1}\right)$ and the detection and quantification limits (LOD and LOQ, respectively) were determined from the parameters of the calibration curves represented in Table 2 (LOD $=3$ standard deviation/slope and $\mathrm{LOQ}=10$ standard deviation/slope). Values of correlation coefficients confirmed linearity of the calibration plots (Table 2). The concentrations of the standards were chosen in order to guarantee the quantification of each compound in the samples by intrapolation in the calibration curve. The results were expressed in $\mathrm{mg}$ of compound/g of extract, as mean values \pm standard deviation $(\mathrm{MV} \pm \mathrm{SD})$ of four independent analyses.

Table 2. Linearity $(y=m x+b$, where y corresponds to the standard peak area/internal standard peak area ratio and $x$ corresponds to the mass of standard/mass of internal standard ratio), LOD and LOQ of pure compounds used as reference.

\begin{tabular}{cccccc}
\hline $\begin{array}{c}\text { Standard } \\
\text { Compound }\end{array}$ & Slope $(\mathbf{m}) \S$ & Intercept (b) $\S$ & $\mathbf{R}^{\mathbf{2}}$ & LOD $\S$ & LOQ $\S$ \\
\hline Palmitic acid & 0.2143 & 0 & 0.9944 & 15 & 50 \\
1-Monopalmitin & 7.2283 & -0.0009 & 0.9975 & 3 & 10 \\
Glycerol & 7.2366 & -0.0037 & 0.9937 & 3 & 10 \\
Triacontane & 2.0154 & -0.0311 & 0.9991 & 10 & 33 \\
Maltose & 4.1401 & -0.0801 & 0.9998 & 3 & 10 \\
Mannose & 4.1380 & -0.1126 & 0.9999 & 5 & 17 \\
$\beta$-Sitosterol & 2.5254 & -0.0033 & 0.9983 & 12 & 40 \\
$\alpha$-Tocopherol & 2.4738 & -0.0028 & 0.9993 & 5 & 17 \\
\hline
\end{tabular}

$\S$ in area counts $\mathrm{mg}^{-1}$; $\S$ in $\mu \mathrm{g} / \mathrm{mL}$.

\subsection{Statistics}

Independent replicates of each sample were analyzed and each aliquot was injected twice. The presented results are the average of four concordant values obtained for each sample (less than $5 \%$ variation between injections of the same aliquot and between aliquots of the same sample) and expressed as mean values \pm standard deviation (MV $\pm \mathrm{SD}$ ). One-way analysis of variance (ANOVA) followed by Duncan's multiple-range test were performed using the GraphPad Prism version 7 for Windows (Graphpad Software, Inc.) to compare the results of each independent replicates. A $p$-value lower than 0.0001 was considered statistically significant in all analyses.

\section{Results and Discussion}

Although the known use of A. quercifolia in traditional medicine $[12,13]$ and a few studies involving GC-MS analysis were reported [23-25], this species still is, from the chemical profile point of view, underexplored. So, both rhizome and leaves were extracted with $n$-hexane at room temperature, aiming to obtain the lipophilic profile. Although 
this type of extraction was not reported for this species, our experience indicates that low extraction yields, such as the ones herein reported (Table 3), are typical in plants growing in warm environments [32]. Nevertheless, it was possible the identification and quantification, using GC-MS, of the major compounds present in both rhizome and leaves extracts, whose chromatograms demonstrate the richness in lipophilic compounds, although some only in traces (Figure 1). This analysis allowed identifying a total of 59 compounds, 31 in rhizome extract, and 34 in leaves extract. These were distributed through several chemical families, explicitly amid fatty acids, short-chain carboxylic acids, carbohydrates, terpenoids, alkanes, and alcohols. The retention time, identification, and content of each compound in $\mathrm{mg} / \mathrm{g}$ of dried rhizome or leaves \pm standard deviation of each species are presented in Table 3 .

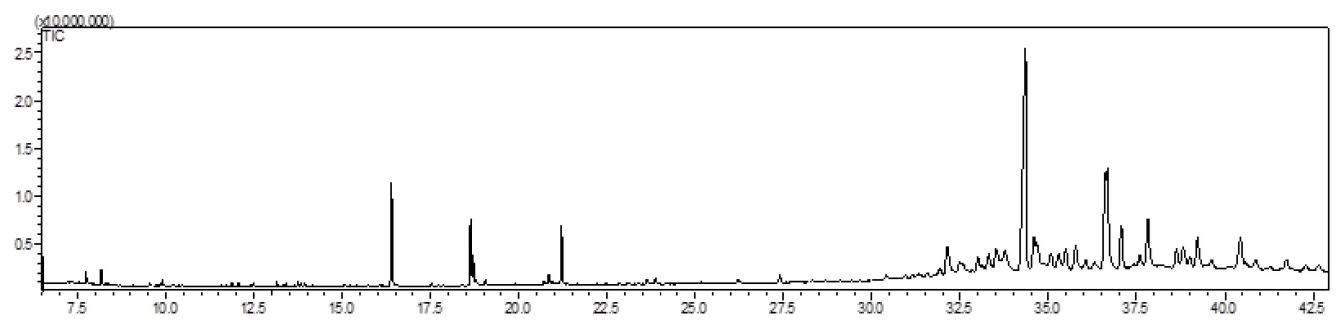

(a)

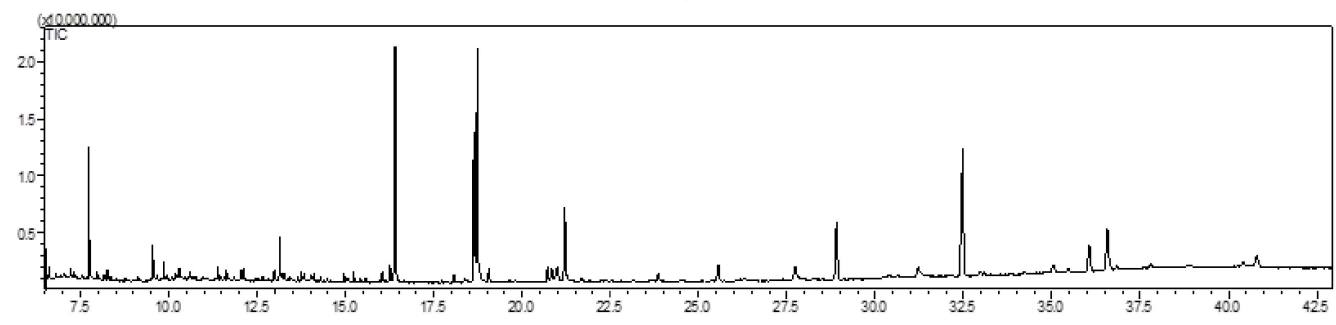

(b)

Figure 1. Total ion chromatogram (TIC) of A. quercifolia rhizomes (a) and leaves (b) $n$-hexane extracts with time in minutes.

Table 3. Identified compounds on the $n$-hexane extract of $A$. quercifolia rhizome and leaves.

\begin{tabular}{|c|c|c|c|c|c|}
\hline Identification * & Rt (min) & RI $_{\text {NIST }}$ & $\mathbf{R I}_{\text {cal }}$ & Rhizome ** & Leaves ** \\
\hline \multicolumn{6}{|c|}{ Carboxylic acids and derivatives } \\
\hline Butanedioic acid ${ }^{b, c, d}$ & 8.26 & 1170 & 1171 & - & $\operatorname{tr}$ \\
\hline Undecanoic acid $\mathrm{b}, \mathrm{c}, \mathrm{d}$ & 9.55 & 1704 & 1704 & - & $21.78 \pm 0.19$ \\
\hline Malic acid a,b,c & 9.86 & 1390 & 1392 & - & $\operatorname{tr}$ \\
\hline L-Glutamic acid $\mathrm{a}, \mathrm{b}, \mathrm{c}$ & 10.30 & - & - & - & $9.87 \pm 0.23$ \\
\hline Shikimic acid $\mathrm{a}, \mathrm{b}, \mathrm{c}$ & 13.14 & 1904 & 1904 & - & $28.58 \pm 0.08$ \\
\hline Citric acid ${ }^{a, b, c}$ & 13.26 & 1944 & 1945 & - & $\operatorname{tr}$ \\
\hline Quininic acid ${ }^{a, b, c}$ & 13.66 & - & - & - & $\operatorname{tr}$ \\
\hline Myristic acid & 13.83 & 1788 & 1787 & - & $\operatorname{tr}$ \\
\hline 3,4-Dihydroxyhydrocinnamic acid ${ }^{a, b, c}$ & 14.96 & 1964 & 1962 & - & $\operatorname{tr}$ \\
\hline Dodecanedioic acid $b, c, d$ & 15.42 & 1965 & 1966 & - & $\operatorname{tr}$ \\
\hline Glucaric acid a,b,c & 15.58 & 2249 & 2250 & - & $\operatorname{tr}$ \\
\hline Oct-3-enoic acid $\mathrm{b}, \mathrm{c}, \mathrm{d}$ & 16.26 & 1200 & 1202 & - & $15.67 \pm 0.09$ \\
\hline Palmitic acid ${ }^{a, b, c}$ & 16.40 & 1987 & 1987 & $107.65 \pm 0.12$ & $237.27 \pm 0.59$ \\
\hline Linoleic acid $\mathrm{a}, \mathrm{b}, \mathrm{c}$ & 18.63 & 2202 & 2202 & $60.97 \pm 0.08$ & $153.81 \pm 0.11$ \\
\hline Linolenic acid ${ }^{a, b, c}$ & 18.73 & 2210 & 2211 & - & $253.71 \pm 0.93$ \\
\hline Oleic acid ${ }^{a, b, c}$ & 18.80 & 2194 & 2192 & $12.33 \pm 0.05$ & $14.48 \pm 0.24$ \\
\hline Stearic acid ${ }^{a, b, c}$ & 19.05 & 2186 & 2184 & $17.00 \pm 0.02$ & $15.49 \pm 0.08$ \\
\hline Arachidonic acid $\mathrm{a}, \mathrm{b}, \mathrm{c}$ & 20.72 & 2417 & 2415 & - & $19.13 \pm 0.04$ \\
\hline Oleoamide (9-Octadecenamide) ${ }^{a, b, c}$ & 20.84 & 2228 & 2230 & - & $13.12 \pm 0.03$ \\
\hline Monopalmitin $\mathrm{a}, \mathrm{b}, \mathrm{c}$ & 23.63 & 2581 & 2583 & $0.50 \pm 0.01$ & - \\
\hline Lignoceric acid a,b,c & 27.75 & 2782 & 2783 & - & $\operatorname{tr}$ \\
\hline
\end{tabular}


Table 3. Cont.

\begin{tabular}{|c|c|c|c|c|c|}
\hline Identification * & Rt (min) & RI $_{\text {NIST }}$ & $\mathrm{RI}_{\text {cal }}$ & Rhizome ** & Leaves** \\
\hline \multicolumn{6}{|c|}{ Terpenoids } \\
\hline Neophytadiene ${ }^{b, c, d}$ & 13.76 & - & 1832 & - & $\operatorname{tr}$ \\
\hline Squalene $\mathrm{b}^{\mathrm{b}, \mathrm{c}, \mathrm{d}}$ & 27.39 & 2914 & 2910 & $2.59 \pm 0.01$ & - \\
\hline Cycloeucalenol acetate derivative ${ }^{b, c, d}$ & 32.13 & - & 2909 & $14.61 \pm 0.02$ & - \\
\hline Stigmastan-3,5-diene ${ }^{\mathrm{c}, \mathrm{d}, \mathrm{e}}$ & 32.47 & 2525 & 2526 & $\operatorname{tr}$ & - \\
\hline$\alpha$-Tocopherol $a, b, c$ & 32.99 & 3226 & 3227 & $6.89 \pm 0.01$ & - \\
\hline Cycloeucalenol acetate ${ }^{b, c, d, \S}$ & 33.29 & 2900 & 2901 & $\operatorname{tr}$ & $\operatorname{tr}$ \\
\hline Serratene ${ }^{b, c, d}$ & 33.53 & 2744 & 2745 & $\operatorname{tr}$ & - \\
\hline Lupeol ${ }^{a, b, c}$ & 33.76 & 2848 & 2845 & $\operatorname{tr}$ & - \\
\hline Hop-16-ene ${ }^{b, c, d}$ & 34.34 & 3420 & 3421 & $166.45 \pm 0.53$ & - \\
\hline Cycloartenol acetate ${ }^{b, c, d}$ & 34.58 & 2907 & 2906 & $9.49 \pm 0.01$ & - \\
\hline 9,19-Cycloergost-24-en-3-ol acetate ${ }^{b, c, d}$ & 34.70 & 2956 & 2957 & $14.58 \pm 0.03$ & - \\
\hline Cholest-5-en-3( $\alpha)$-ol ${ }^{b, c, d}$ & 35.07 & 2954 & 2955 & $16.49 \pm 0.02$ & - \\
\hline Lupenone ${ }^{b, c, d}$ & 35.28 & 3483 & 3481 & $7.22 \pm 0.01$ & - \\
\hline Stigmasterol $a, b, c$ & 35.48 & 2797 & 2796 & $9.44 \pm 0.01$ & - \\
\hline $\begin{array}{l}\text { 4,14-Dimethyl-9,19-cyclolanost- } \\
\text { 24(28)-en-3-ol b,c,d }\end{array}$ & 35.76 & 2760 & 2761 & $10.75 \pm 0.01$ & - \\
\hline$\gamma$-Sitosterol ${ }^{\mathrm{a}, \mathrm{b}, \mathrm{c}}$ & 36.05 & 2731 & 2731 & $12.11 \pm 0.05$ & - \\
\hline$\beta$-Sitosterol a,b,c & 36.60 & 2789 & 2789 & $50.76 \pm 0.11$ & - \\
\hline Hop-21-ene ${ }^{b, c, d}$ & 36.67 & 2659 & 2659 & $6.23 \pm 0.01$ & - \\
\hline Diploptene [Hop-22(29)-ene] ${ }^{b, c, d}$ & 37.06 & - & 2667 & $48.01 \pm 0.13$ & - \\
\hline Cycloeucalenone ${ }^{b, c, d}$ & 37.81 & - & 2981 & $26.75 \pm 0.02$ & - \\
\hline $\begin{array}{l}\text { 9,19-Cyclolanost-23-ene-3,25-diol } \\
\text { 3-acetate }{ }^{\mathrm{b}, \mathrm{c}, \mathrm{d}, \S} \mathrm{S}\end{array}$ & 38.62 & 3071 & 3070 & $12.99 \pm 0.01$ & - \\
\hline Hop-17(21)-ene ${ }^{\mathrm{b}, \mathrm{c}, \mathrm{d}}$ & 38.80 & - & 2672 & $14.99 \pm 0.01$ & - \\
\hline 3-O-Acetyl-6-methoxycycloartenol b,c,d & 39.01 & 3093 & 3091 & $5.94 \pm 0.02$ & - \\
\hline Cyclolaudenol ${ }^{\mathrm{b}, \mathrm{c}, \mathrm{d}}$ & 39.21 & 2834 & 2834 & $19.32 \pm 0.06$ & - \\
\hline Campesterol $\mathrm{a}, \mathrm{b}, \mathrm{c}$ & 39.62 & 2689 & 2685 & $25.64 \pm 0.12$ & $\operatorname{tr}$ \\
\hline 31-Norcyclolaudenone ${ }^{b, c, d}, \S \S$ & 40.43 & - & 3095 & $21.05 \pm 0.06$ & - \\
\hline \multicolumn{6}{|c|}{ Alcohols } \\
\hline Glycerol $^{\mathrm{a}, \mathrm{b}, \mathrm{c}}$ & 7.74 & - & - & - & $0.39 \pm 0.01$ \\
\hline Pentitol $b, c, d$ & 12.13 & - & - & - & $0.95 \pm 0.01$ \\
\hline Phytol ${ }^{b, c, d}$ & 18.07 & 2086 & 2086 & - & $16.43 \pm 0.05$ \\
\hline \multicolumn{6}{|c|}{ Alkanes } \\
\hline$n$-Docosane $\mathrm{e}^{\mathrm{e}}$ & 25.56 & - & - & - & $5.02 \pm 0.02$ \\
\hline$n$-Octacosane $\mathrm{e}^{\mathrm{a}}$ & 28.91 & - & - & - & $38.05 \pm 0.03$ \\
\hline$n$-Tritetracontane $\mathrm{b}^{\mathrm{b}, \mathrm{c}, \mathrm{d}}$ & 32.48 & - & - & - & $131.35 \pm 0.64$ \\
\hline$n$-Hentriacontane ${ }^{b, c, d}$ & 36.06 & - & - & - & $13.04 \pm 0.05$ \\
\hline \multicolumn{6}{|c|}{ Carbohydrates } \\
\hline D-Psicofuranose ${ }^{b, c, d}$ & 12.99 & 2029 & 2029 & - & $1.73 \pm 0.02$ \\
\hline D-Tagatose $b, c, d$ & 14.03 & 1982 & 1980 & - & $\operatorname{tr}$ \\
\hline D-Galactose ${ }^{\mathrm{a}, \mathrm{b}, \mathrm{c}}$ & 14.11 & 1970 & 1973 & - & $\operatorname{tr}$ \\
\hline D-Glucose $\mathrm{a}, \mathrm{b}, \mathrm{c}$ & 15.23 & 2037 & 2035 & - & $5.76 \pm 0.04$ \\
\hline Sucrose ${ }^{a, b, c}$ & 23.86 & 3552 & 3551 & $1.97 \pm 0.01$ & - \\
\hline
\end{tabular}

$\mathrm{RT}=$ retention time; $\mathrm{RI}_{\mathrm{NIST}}=\mathrm{NIST} 14$ mass spectral data retention index; $\mathrm{RI}_{\text {cal }}=$ retention index relative to $n$-alkanes $\left(\mathrm{C}_{5}-\mathrm{C}_{36}\right) ; \mathrm{MV}=$ mean value; $\mathrm{SD}=$ standard deviation; - = not found; $\mathrm{tr}=$ traces; ${ }^{*}$ all compounds possessing hydroxy groups are identified as the correspondent TMS derivatives. Compounds were identified by: ${ }^{a}$ comparison with pure silylated standards, ${ }^{b}$ comparison with the GC-MS spectral libraries NIST14.lib and WILEY229.lib, ${ }^{c}$ comparison with spectra found in the literature, ${ }^{\mathrm{d}}$ interpretation of MS spectrum fragmentation pattern; ${ }^{\mathrm{e}}$ comparison with pure standards; ${ }^{* *}$ Values in MV $\pm \mathrm{SD} ;{ }^{\S}(3 \beta, 4 \alpha, 5 \alpha, 9 \beta)-4,14$-dimethyl-9,19-cycloergost-24(28)-en-3-yl acetate; $\$ \S$ 4-Monomethylcycloartane.

It is evident that the rhizomes and leaves lipophilic profiles are not very rich in secondary metabolites (Figure 1). Different results were observed regarding the mass of compounds identified in each extract, $70.3 \%$ in rhizomes and $99.6 \%$ in leaves. However, the percentage of compounds not identified by GC-MS was, therefore, approximately $30 \%$ for rhizome and less than $1 \%$ for leaves. 
Regarding rhizomes extract, the most abundant chemical family present is terpenoids $(50.2 \%)$, which included diterpenes, triterpenes, and steroids (Table 3, Figure 2). The rhizome chemical profile was dominated by hop-16-ene (166.45 $\pm 0.53 \mathrm{mg} / \mathrm{g}$ dry rhizome) and $\beta$-sitosterol (50.76 $\pm 0.11 \mathrm{mg} / \mathrm{g}$ dry rhizome). The second major chemical family identified in this plant part lipophilic extract was carboxylic acids and derivatives, summing a total of $19.8 \%$ of the identified compounds (Figure 2). The fatty acids palmitic and linoleic dominated the family with $107.65 \pm 0.12 \mathrm{mg} / \mathrm{g}$ dry rhizome and $60.97 \pm 0.08 \mathrm{mg} / \mathrm{g}$ dry rhizome, respectively (Table 3).

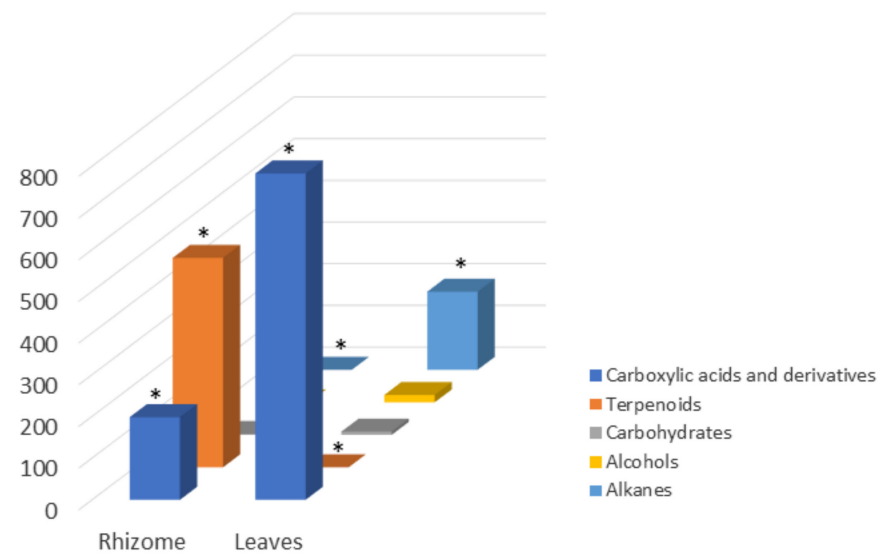

Figure 2. Graphical presentation of the total amount of each class of compounds for the two studied plant parts. * Statistically different (Tukey's test) $p<0.001$.

Leaves extract showed more diversity in the chemical families present and their representativity (Figure 2). The major chemical family in its lipophilic extract, representing $78.3 \%$ of the identified compounds, was the carboxylic acids and derivatives. In addition, among the identified compounds, palmitic, linolenic, and linoleic acids were the ones found in the highest amount, respectively $237.27 \pm 0.59 \mathrm{mg} / \mathrm{g}$ dry leaves, $253.71 \pm 0.93 \mathrm{mg} / \mathrm{g}$ dry leaves, and $153.81 \pm 0.11 \mathrm{mg} / \mathrm{g}$ dry leaves (Table 3). Alkanes were the second major class observed, representing $18.7 \%$ of the identified compounds (Figure 2), being the $n$-tritetracontane found in significant quantities $(131.3 \pm 0.64 \mathrm{mg} / \mathrm{g}$ dry leaves). The remaining chemical families represent $0.2 \%$ and $2.5 \%$ of the rhizome and leaves' identified compounds, respectively (Figure 2).

Alkanes represent more than $70 \%$ of the wax cuticle constitution, which is indispensable to prevent water loss [33], so their detection in A. quercifolia leaves seems quite normal. $n$-Alkanes are easily distinguishable by their mass spectrum due to the first fragment ion peak, represented by $[\mathrm{M}-29]^{+}$ion (loss of a ${ }^{\bullet} \mathrm{CH}_{2} \mathrm{CH}_{3}$ ), the base peak occurs at 43 or $57 \mathrm{~m} / \mathrm{z}$, and peaks differing by $14 \mathrm{~m} / z$ units (e.g., $43,57,71,85$, etc.) are present [34]. Nevertheless, their identification was possible mainly using pure standards and comparing with GC-MS databases.

A detailed analysis of Table 3 shows that $A$. quercifolia leaves are incredibly rich in fatty acids, both saturated fatty acids (SFA) and polyunsaturated fatty acids (PUFA), from which, respectively, palmitic acid (237.27 $\pm 0.59 \mathrm{mg} / \mathrm{g}$ dry leaves) and linolenic acid ( $253.71 \pm 0.93 \mathrm{mg} / \mathrm{g}$ dry leaves) can be highlighted (Table 3). The plant rhizome also presents a high quantity of palmitic acid (107.65 $\pm 0.12 \mathrm{mg} / \mathrm{g}$ dry rhizome), contributing to a higher amount of SFA compared to PUFA (Table 3). However, it should be emphasized that recent evidence points out that SFA in the human diet may not have such an adverse health effect [35]. In the case of leaves, it is evident that some nutritional indexes, such as $\omega-6 / \omega-3$ (total of omega- 6 acids/total of omega- 3 acids ratio), atherogenicity index (AI), and thrombogenicity index $(\mathrm{TI})$, present values $(\omega-6 / \omega-3=0.68 ; \mathrm{AI}=0.59 ; \mathrm{TI}=0.30)$ that suggest nutritional and health-promoting values [36,37].

Concerning the rhizome, it is evident its richness in terpenoid derivatives (Figure 2), from which cycloartane, hopanoid, and phytosterol derivatives can be highlighted and 
being the major compounds hop-16-ene ( $166.45 \pm 0.53 \mathrm{mg} / \mathrm{g}$ dry rhizome), $\beta$-sitosterol ( $50.76 \pm 0.11 \mathrm{mg} / \mathrm{g}$ dry rhizome), diploptene (48.01 $\pm 0.13 \mathrm{mg} / \mathrm{g}$ dry rhizome), cycloeucalenone ( $26.75 \pm 0.02 \mathrm{mg} / \mathrm{g}$ dry rhizome), campesterol ( $25.64 \pm 0.12 \mathrm{mg} / \mathrm{g}$ dry rhizome), and 31-norcyclolaudenone (21.05 $\pm 0.06 \mathrm{mg} / \mathrm{g}$ dry rhizome) (Table 3 and Figure 3).

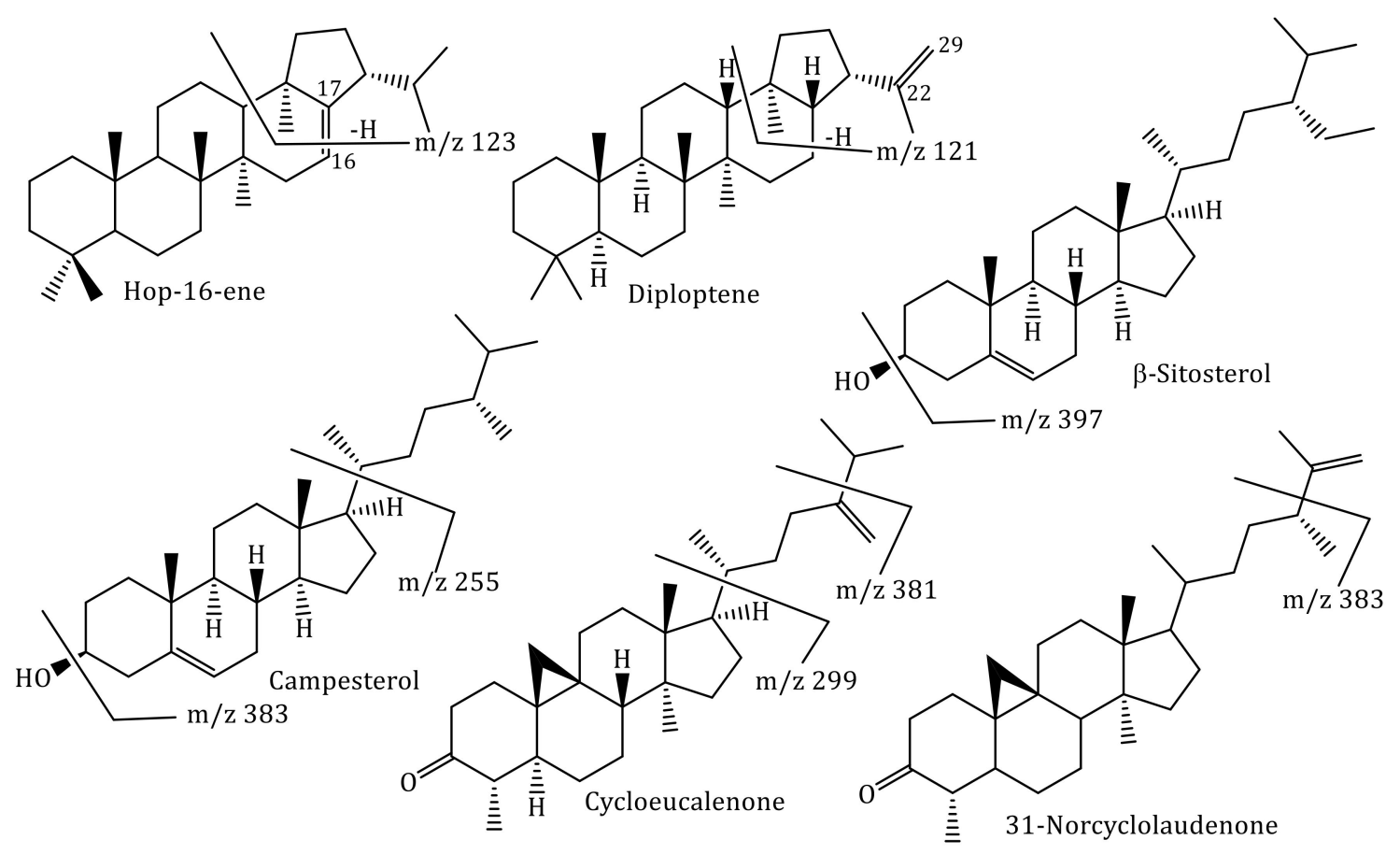

Figure 3. Chemical structure of some of the identified terpenoids and some of the most significant fragments.

Some of the terpenoids found in A. quercifolia rhizomes are commonly found in plants, including some phytosterols found in our previous works [32,38]. Cycloartane triterpenoids' natural occurrence is also vast through the plant kingdom [39], being cycloartenol the most recognized due to its rule in the phytosterols biosynthesis [40] and consequently in the regulation of important plant functions [41]. The occurrence of this type of triterpenoids in A. quercifolia rhizomes (Table 3) may explain the effect that the rhizome intake promotes on young moms. Actually, there are references to the use of several plants to improve breastfeeding [42-44] and evidence that terpenoids are also involved [42,43].

Lastly, it seems imperative to mention the hopanoids triterpenes, which are the major class found in A. quercifolia rhizomes, mainly due to the presence of hop-16-ene (Table 3 and Figure 3). This type of triterpenes frequently occurs in ferns and was described for the first time by John Hope, a British botanist [45,46]. Several hopanoids, including hop-16-ene and diploptene (Figure 3), were found in Davallia mariesii rhizomes, and our results are identical to those previously reported [47]. The mass fragments confirm, in particular, the position of the double bond at C16 = C17 in hop-16-ene and C22 = C29 in diploptene (Figure 3). Moreover, the NMR data showed a proton sign at $\delta 5.28 \mathrm{ppm}$ correlated with a carbon sign at $\delta 115.6 \mathrm{ppm}$ characteristics of the hop-16-ene vinylic proton and carbon. Whereas in the case of diploptene, it is possible to detect the vinylic proton and carbon, respectively, at $\delta 4.78$ and $\delta 109.9 \mathrm{ppm}$, data that are similar to the ones previously reported [47]. It is also important to highlight that the hop-16-ene DEPT 90 and DEPT 135 spectra confirm the presence of 6 methine, 10 methylene, and 8 methyl carbons, data that also ensure the proposed structure (Figure 3).

\section{Conclusions}

The A. quercifolia rhizomes and leaves GC-MS profiles were established and revealed the plant nutritional value. Almost all the compounds herein reported were found for 
the first time in the species. The leaves richness in PUFA should be highlighted not only because it attests to their nutritional value but also will incentive its use in Timorese cuisine. The rhizomes richness in terpenoids should also be emphasized, particularly the cycloartane derivatives, compounds involved in phytosterols' biosynthesis, which validate this plant's use of rhizome to incentive the production of milk by young moms. The hopanoid derivatives herein revealed for the first time in this species, although common in ferns, may differentiate the species.

Author Contributions: Conceptualization, D.C.G.A.P. and A.M.S.S.; methodology, H.R.C. and D.C.G.A.P.; formal analysis, D.C.G.A.P. and A.M.S.S.; writing-original draft preparation, I.S. and D.C.G.A.P.; writing-review and editing, D.C.G.A.P., I.S., H.S., P.S. and A.M.S.S.; supervision, D.C.G.A.P.; funding acquisition, H.S. and A.M.S.S. All authors have read and agreed to the published version of the manuscript.

Funding: This research was funded by FCT/MCT, which gives the financial support to LAQVREQUIMTE (UIDB/50006/2020 + UIDP/50006/2020) and to FCT/MCTES for the financial support to CESAM (UIDP/50017/2020+UIDB/50017/2020), through national funds.

Institutional Review Board Statement: Not applicable.

Informed Consent Statement: Not applicable.

Data Availability Statement: Not applicable.

Acknowledgments: Thanks are due to the University of Aveiro, FCT/MCT and FEDER, within the PT2020 Partnership Agreement, and to the Portuguese NMR Network, for their support. Thanks, are also due to U.N.T.L. (Dili, East Timor) for a grant attributed to H.R. Costa.

Conflicts of Interest: The authors declare no conflict of interest.

\section{References}

1. Lindsay, S.; Hovenkamp, P.H.; Middleton, D.J. New combinations and typifications in Aglaomorpha (Polypodiaceae). Gard. Bull. Singapore 2017, 69, 149-155. [CrossRef]

2. Hovenkamp, P.H. Polypodiaceae. In Flora Malesiana, Seri II-Pteridophyta; Kalkman, C., Kirkup, D.W., Nooteboon, H.P., Saw, L.G., Stevens, P.F., Wilde, W.J.J., Eds.; New York Botanical Garden: New York, NY, USA, 1998; Volume 3, pp. 1-234.

3. PPG. A community-derived classification for extant lycophytes and ferns. J. Systemat. Evolut. 2016, 54, 563-603. [CrossRef]

4. Kalaiselvan, M.; Gopalan, R. Ethnobotanical studies on selected wild medicinal plants used by Irula tribes of Bolampatty Valley, Nilgiri Biosphere Reserve (NBR), Southern Western Ghats, India. Asian J. Pharm. Clin. Res. 2014, 7, $22-26$.

5. Das, H.B.; Majumdar, K.; Datta, B.K.; Ray, D. Ethnobotanical uses of some plants by Tripuri and Reang tribes of Tripura. Nat. Prod. Rad. 2009, 8, 172-180.

6. Sen, A.; Ghosh, P.D. A note on the ethnobotanical studies of some pteriddophytes in Assam. Indian J. Tradit. Knowwl. 2011, 10, 292-295.

7. Ramanathan, R.; Bhuvaneswari, R.; Indhu, M.; Subramanian, G.; Dhandapani, R. Survey of ethnobotanical observation on wild tuberous medicinal plants of Kollihills, Namakkal district, Tamilnadu. J. Med. Plants Stud. 2014, 2, 50-58.

8. Rahmatullah, M.; Jahan, R.; Seraj, S.; Islam, F.; Jahan, F.I.; Khatun, Z.; Sanam, S.; Monalisa, M.N.; Khan, T.; Biswas, K.R. Medicinal Plants Used by Folk and Tribal Medicinal Practitioners of Bangladesh for Treatment of Gonorrhea. Am Eurasian J. Sustain. Agric. 2011, 5, 276-281.

9. Rahmatullah, M.; Mukti, I.J.; Haque, A.; Mollik, M.D.; Parvin, K.; Jahan, R.; Chowdhury, M.H.; Rahman, T. An Ethnobotanical Survey and Pharmacological Evaluation of Medicinal Plants used by the Garo Tribal Community living in Netrakona district, Bangladesh. Adv. Nat. App. Sci. 2009, 3, 402-418.

10. Rahmatullah, M.; Azam, M.D.; Khatun, Z.; Seraj, S.; Islam, F.; Rahman, M.D.; Jahan, S.; Aziz, M.D.S. Medicinal plants used for treatment of diabetes by the Marakh sect of the Garo tribe living in Mymensingh district, Bangladesh. Afr. J. Tradit. Complement. Alternat. Med. 2012, 9, 380-385. [CrossRef]

11. Mollik, A.; Hasan, N.; Hossan, S.; Jahan, R.; Rahmatullah, M. Medicinal plants used against malaria in several regions of Bogra district, Bangladesh. Planta Med. 2009, 75, PD39. [CrossRef]

12. Costa, H.R. The Pteridophytes of Timor, with Special Focus on Timor-Leste. Ph.D. Thesis, University of Aveiro, Aveiro, Portugal, 2021.

13. Taek, M.M.; Prajogo, B.E.W.; Agil, M. Plants used in traditional medicine for the treatment of malaria by the Tetun ethnic people in West Timor Indonesia. Asian Pac. J. Trop. Med. 2018, 11, 630-637. [CrossRef]

14. Prasanna, G.; Anuradha, R. Evaluation of in vitro antioxidant activity of rhizome extract of Drynaria quercifolia L. Int. J. Chem. Tech. Res. 2015, 8, 183-187. 
15. Mithraja, M.J.; Irudayaraj, V.; Kiruba, S.; Jeeva, S. Antibacterial efficacy of Drynaria quercifolia (L.) J. Smith (Polypodiaceae) against clinically isolated urinary tract pathogens. Asian Pac. J. Trop. Biomed. 2012, 2, S131-S135. [CrossRef]

16. Anuja, G.I.; Latha, P.G.; Shine, V.J.; Suja, S.R.; Shikha, P.; Kumar, K.S.; Rajasekharan, S. Antioedematous and Analgesic Properties of Fertile Fronds of Drynaria quercifolia. ISRN Inflammation 2014, 2014, 1-8. [CrossRef]

17. Anuja, G.I.; Latha, P.G.; Suja, S.R.; Shyamal, S.; Shine, V.J.; Sini, S.; Pradeep, S.; Shikha, P.; Rajasekharan, S. Anti-inflammatory and analgesic properties of Drynaria quercifolia (L.) J. Smith. J. Ethnopharmacol. 2010, 132, 456-460. [CrossRef]

18. Kulkarni, G.K.; Kadolkar, R.V.; Maisale, A.B. Anthelmintic activity of Drynaria quercifolia (L.) J. Smith. J. Pharm. Res. 2010, 3, 975-977.

19. Khan, A.; Haque, E.; Mukhlesur, R.M.; Mosaddik, A.; Rahman, M.; Sultana, N. Isolation of antibacterial constituent from rhizome of Drynaria quercifolia and its sub-acute toxicological studies. DARU J. Fac. Pharm. 2007, 15, 205-211.

20. Saravanan, S.; Mutheeswaran, S.; Saravanan, M.; Chellappandian, M.; Paulraj, M.G.; Raj, M.K.; Ignacimuthua, S.; Duraipandiyanac, V. Ameliorative effect of Drynaria quercifolia (L.) J. Sm., an ethnomedicinal plant, in arthritic animals. Food Chem. Toxicol. 2013, 51, 356-363. [CrossRef]

21. Pagare, S.; Bhatia, M.; Tripathi, N.; Pagare, S.; Bansal, Y.K. Secondary Metabolites of Plants and their Role: Overview. Curr. Trends Biotechnol. Pharm. 2015, 9, 293-304.

22. Erb, M.; Kliebenstein, D.J. Plant secondary metabolites as defenses, regulators, and primary metabolites: The blurred functional trichotomy. Inaugural Trop. Rev. Plant Physiol. 2020, 184, 39-52. [CrossRef]

23. Prasanna, G.; Chitra, M. Phytochemical screening and GC-MS analysis of Drynaria quercifolia rhizome. Am. J. Adv. Drug Deliv. 2014, 3, 72-78.

24. Rajesh, K.D.; Subramanian, V.; Panneerselvam, A.; Rajesh, N.V.; Jeyathilakan, N. GC-MS analysis of secondary metabolites from the whole plant methanolic extract of Drynaria quercifolia (L.) J. Smith (Polypodiaceae). J. Adv. Appl. Scientif. Res. 2016, 1, 84-89.

25. Nithin, M.K.; Veeramani, G.; Sivakrishnan, S. Phytochemical screening and GC-MS analysis of rhizome of Drynaria quercifolia. Res. J. Pharm. Tech. 2020, 13, 2266-2268. [CrossRef]

26. Füzfai, Z.; Boldizsár, I.; Molnar-Perl, I. Characteristic fragmentation patterns of the trimethylsilyl and trimethylsilyl-oxime derivatives of various saccharides as obtained by gas chromatography coupled to ion-trap mass spectrometry. J. Chromatogr. A 2008, 1177, 183-189. [CrossRef]

27. Razboršek, M.I.; Vončina, D.B.; Doleček, V.; Vončina, E. Determination of oleanolic, betulinic and ursolic acid in lamiaceae and mass spectral fragmentation of their trimethylsilylated derivatives. Chromatographia 2008, 67, 433-440. [CrossRef]

28. Suttiarporn, P.; Chumpolsri, W.; Mahatheeranont, S.; Luangkamin, S.; Teepsawang, S.; Leardkamolkarn, V. Structures of phytosterols and tripernoids with potential anti-cancer activity in bran of black non-glutinous rice. Nutrients 2015, 7, 1672-1687. [CrossRef]

29. AOCS Lipid Library, Lipid Chemistry, Biology, Technology \& Analysis. Available online: http://lipidlibrary.aocs.org/index.html (accessed on 15 November 2020).

30. Golm Metabolome Database (GMD). Available online: http://gmd.mpimp-golm.mpg.de/ (accessed on 15 November 2020).

31. Nič, M.; Jirát, J.; Košata, B.; Jenkins, A.; McNaught, A. Compendium of Chemical Terminology; IUPAC: Research Triangle Park, NC, USA, 2009.

32. Rahmouni, N.; Pinto, D.C.G.A.; Santos, S.A.O.; Beghidja, N.; Silva, A.M.S. Lipophilic composition of Scabiosa stellata L.: An underexploited plant from Batna (Algeria). Chem. Pap. 2018, 72, 753-762. [CrossRef]

33. Bourdenx, B.; Bernard, A.; Domergue, F.; Pascal, S.; Léger, A.; Roby, D.; Pervent, M.; Vile, D.; Haslam, R.P.; Napier, J.A.; et al. Overexpression of Arabidopsis ECERIFERUM1 promotes wax very-long-chain alkane biosynthesis and influences plant response to biotic and abiotic stresses. Plant Physiol. 2011, 156, 29-45. [CrossRef]

34. Sparkman, O.D.; Penton, Z.E.; Kitson, F.G. Hydrocarbons. In Gas Chromatography and Mass Spectrometry: A Practical Guide; Sparkman, O.D., Penton, Z.E., Kitson, F.G., Eds.; Elsevier: Burlington, MA, USA, 2011; pp. 331-339.

35. Agostoni, C.; Moreno, L.; Shamir, R. Palmitic acid and health: Introduction. Crit. Rev. Food Sci. Nutr. 2016, 56, 1941-1942. [CrossRef]

36. Ulbricht, T.L.V.; Southgate, D.A.T. Coronary heart disease: Seven dietary factors. Lancet 1991, 338, 985-992. [CrossRef]

37. Simopoulos, A.P. The importance of the omega-6/omega-3 fatty axid ratio in cardiovascular disease and other chronic diseases. Exp. Biol. Med. 2008, 233, 674-678. [CrossRef]

38. Faustino, M.V.; Faustino, M.A.F.; Silva, H.; Silva, A.M.S.; Pinto, D.C.G.A. Lipophilic metabolites of Spartina maritima and Puccinellia maritima involved in their tolerance to salty environments. Chem. Biodiversity 2020, 17, e2000316. [CrossRef]

39. Boar, R.B.; Roner, C.R. Cycloartane triterpenoids. Phytochemistry 1975, 14, 1143-1146. [CrossRef]

40. Myant, N.B. The Biosynthesis of Sterols. In The Biology of Cholesterol and Related Steroids; Elsevier Ltd.: Amsterdam, The Netherlands, 1981; Chapter 4; pp. 161-225.

41. Clouse, S.D. Brassinosteroids. Ref. Module Biomed. Sci. 2019. [CrossRef]

42. Kuswaningrum, O.; Suwandono, A.; Ariyanti, I.; Hadisaputro, S.; Suharttono, S. The impact of consuming Amaranthus spinosus L. extract on prolactin level and breast milk production in postpartum mothers. Belitung Nurs. J. 2017, 3, 541-547. [CrossRef]

43. Bekoe, E.O.; Kitcher, C.; Gyima, N.A.M.; Schwingee, G.; Frempong, M. Medicinal plants used as galactagogues. In PharmacognosyMedicinal Plants; IntechOpen: London, UK, 2018. [CrossRef] 
44. Jendras, G.; Monizi, M.; Neinhuis, C.; Lautenschläger, T. Plants, food and treatments used by BaKongo tribes in Uíge (northern Angola) to affect the quality and quantity of human breast milk. Int. Breastfeeding J. 2020, 15, 88. [CrossRef]

45. Poralla, K. Cycloartenol and other triterpene cyclases. Compr. Nat. Prod. Chem. 1999, 2, 299-319.

46. Kushiro, T.; Ebizuka, Y. Triterpenes. In Comprehensive Natural Products II: Chemistry and Biology; Elsevier Ltd.: London, UK, 2010; pp. 673-708.

47. Shiojima, K.; Ageta, H. Fern constituents: Two new triterpenoid hydrocarbons, hop-16-ene and isohop-22(29)-ene, isolated from Davallia mariesii. Chem. Pharm. Bull. 1999, 38, 347-349. [CrossRef] 